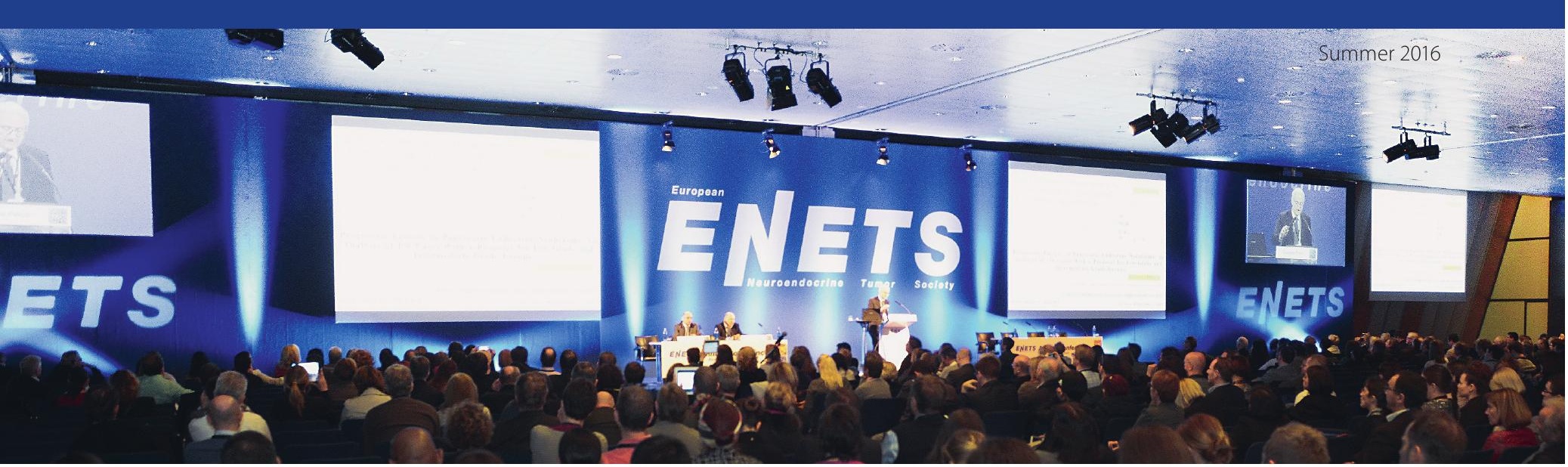

\title{
Letter from the Chairman
}

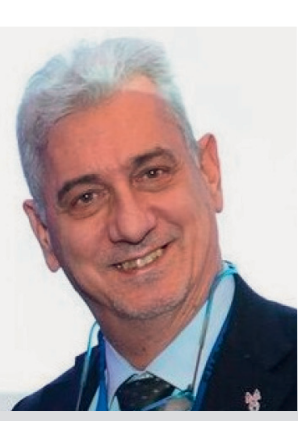

Prof. Massimo Falconi, ENETS Chairman

Dear colleagues and friends,

Since the winter and early spring months 2016, ENETS has been very productive. I am, therefore, delighted to inform you about the many events that have taken place during that time in this newsletter. As the new Chairman of ENETS, I am very pleased to take on this role and hope you will join me in the next years in further contributing and transforming ENETS into a multi-disciplinary and international society.

On this note, I would like to thank Prof. Martyn Caplin for his recent term as ENETS Chairman (2014-2016) and for his immense dedication in bringing new and improved changes to ENETS by restructuring and opening the society to members from all over the world. His past endeavors included updating the ENETS educational channel (NET-CME), creating new collaborations with other societies, strengthening ENETS Centers of Excellence (CoE), initiating the application process for the European Reference Network (ERN), further opening the doors to young investigators and researchers, and finally developing and improving Standards of Care and

ENETS Guidelines. For the latter, I am truly happy to announce that the updated ENETS Guidelines have been published in April 2016 and that the ENETS Standards of Care are planned to be published later in this year in the Neuroendcrinology. In this respect, I would like to thank all Advisory Board Members for their needed contributions and efforts as working group members, authors and co-authors.

Please read through the newsletter below, as it will offer you a report on highlights from the 'ENETS 13th Annual Conference from 9-11 March, 2016', 'ENETS Guidelines', 'European Reference Network (ERN)` as well as updates on the ENETS Centers of Excellence (CoE), 'NET Nurse', membership area 'MY ENETS' and much more.

I am very much looking forward to hearing from you in the next years.

Yours,

Massimo Falconi

(ENETS Chairman)

\section{In this Newsletter}

13th Annual ENETS Conference Postgraduate Course 2016

Highlight: Main Conference 2016

Life Achievement Award 2016 ENETS NET Nurse Symposium
ENETS Grant Awards ENETS Guidelines 2016

European Reference Network (ERN) Centers of Excellence (CoE) MY ENETS
ENETS NET Summer School

Save the Dates!

Conference Photos at a Glance 


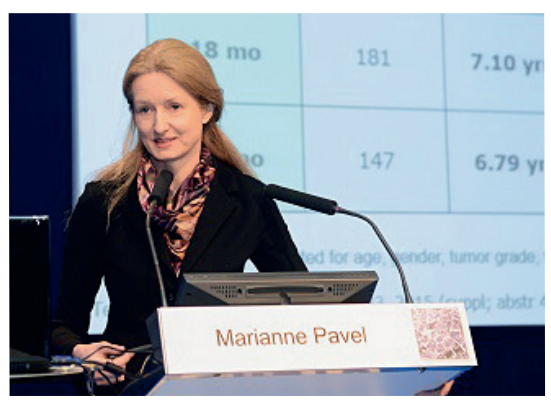

Prof. Marianne Pavel

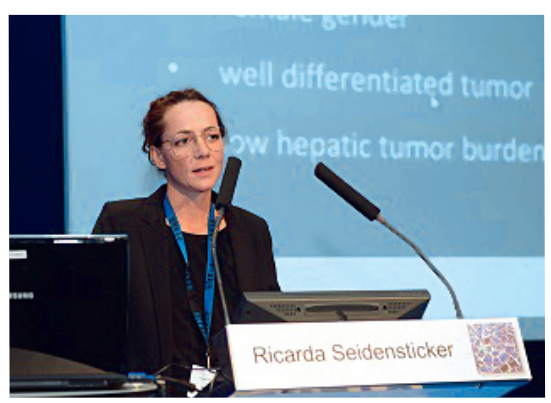

Dr. Ricarda Seidensticker

\section{Report on the 13th Annual ENETS Conference, Barcelona Spain, 9-11 March 2016}

ENETS would like to point out that the 13th Annual ENETS Conference (9-11th March 2016) was well reviewed by 1,500 participants from 55 different countries worldwide. On behalf of the ENETS Executive Committee, Prof. Falconi would like to express his gratitude and thanks to all lecturers and chairs for their impressive contributions, as well as to the Abstract and Grant Reviewing Committees. Special thanks go to the organizing team, who in their 13th year, have proven again that superb planning and continued improvements lead to a successful event. ENETS would also like to express much needed thanks to the support by Novartis (Platinum), Ipsen (Gold), Pfizer (Silver) and AAA (Bronze). Special thanks also goes to the exhibitors Novartis, Ipsen, Pfizer, AAA, Sirtex, Wisepress and Delcath. In addition, ENETS thanks INCA and the NET Patient Foundation for their important presence and participation, as well as the non-profit organizations NET Research Foundation and Bioscientifica. Last but not least, ENETS thanks the participants (clinicians, researchers, young investigators and nurses) for attending and enabling the ENETS conference program by reaching out to them to gain knowledge in NET, and implementing this acquired knowledge on patients to ensure best practice.

\section{Postgraduate (PG) Course}

660 participants visited the 6th Annual Postgraduate Course on March 9th 2016. The Postgraduate Course participants were offered detailed expertise in various medical fields. For further educational purposes, the participants were handed out materials in the form of presentations including specially designed learning points. As a result, the feedback survey was positively reviewed for all of the speeches.

Prof. Marianne Pavel (see photo above) opened the Postgraduate Course with the first speech titled 'Somatostatin Analogues AntitumorEffect: More Understanding in the Last Year'. Her talk covered topics such as 'Updated results from placebo-controlled trials' including long term survival data from the 'PROMID study, results from the CLARINET extension

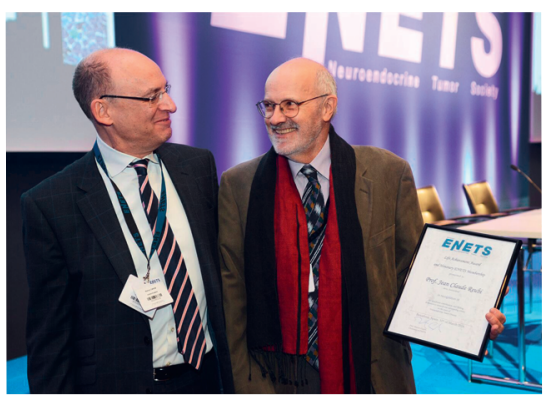

Prof. Jean Claude Reubi (right) receiving the award from Prof. Martyn Caplin (left)

study, and from the study updates and providing new conclusions, she highlighted how results from the CLARINET Study had an impact on the recently released ENETS Consensus Guidelines and as such defined the use of SSA as 1st line therapy not only in midgut but also in pNET patients'.

Furthermore, the talk by Dr. Ricarda Seidensticker (see photo left) titled 'Locoregional Therapy for Liver Disease: Transarterial Embolization, Yttrium90-Radioembolization, Radiofrequency Ablation' covered interesting radiological aspects. An excerpt from her summary briefly describes the first part of her talk: 'Within the therapeutic armamentarium needed in GEP-patients suffering from hepatic metastases, local and locoregional interventions provide tools to increase local control and relief hormonally related symptoms due to hepatic cytoreduction which might be associated with improved long-term survival, although the data are mostly retrospective and need to be interpreted with caution'.

Please note that the PG participants from 2016 can view the talks via a special internal password protected ENETS webpage at anytime and can contact the speakers directly for follow-up communication. Please contact ENETS to find out more at info@enets.org.

\section{Main Conference Highlights}

The conference opened with Session 1, which covered 'Pathology Aspects on NET'. The talk opened by Prof. Aurel Perren (current ENETS Scientific Secretary) from the University of Bern in Switzerland titled 'Profiling in GEPNET', gave an insight into 'Aims of profiling' and laid out these aims by explaining in detail that 'a better stratification of tumor, molecular classification allowing for better response prediction' as well as, but not limited to 'profiling on DNA-level (NGS based whole exome/genome sequencing) identifies driver mutations', and that 'expression analysis identifies clusters, groups of tumors with similar pathways active'.

\section{Life Achievement Award}

The first session was followed by the Life Achievement Award, which was awarded to Prof. Jean Claude Reubi (see photo above) from Switzerland, who is considered the father of peptide-receptors in diagnostics and fherapy. Prof. Christ's dedication explained that Prof. Reubi's main focus of research was to establish the role of peptide receptors on tumors tissue for diagnostics and therapy. He added that, 'using the method of autoradiography by Prof. Reubi, determined the incidence and density of receptors on a panoply of tumor tissues in vitro, with protagonists as well as antagonists of the corresponding receptors. Regarding NET his work was instrumental for the therapy in secreting NETs using SST-Analoga, for diagnostics using Ocetroscan and later 68Ga-DOTATATE PET, for therapy using Yttrium and Lutetium, and recently, for the anatgonists that appear to have a significant potential, in particular also for therapy.' Additionally regarding NET, he led the basis of GLP-1R imaging in benign insulinoma and the potential 

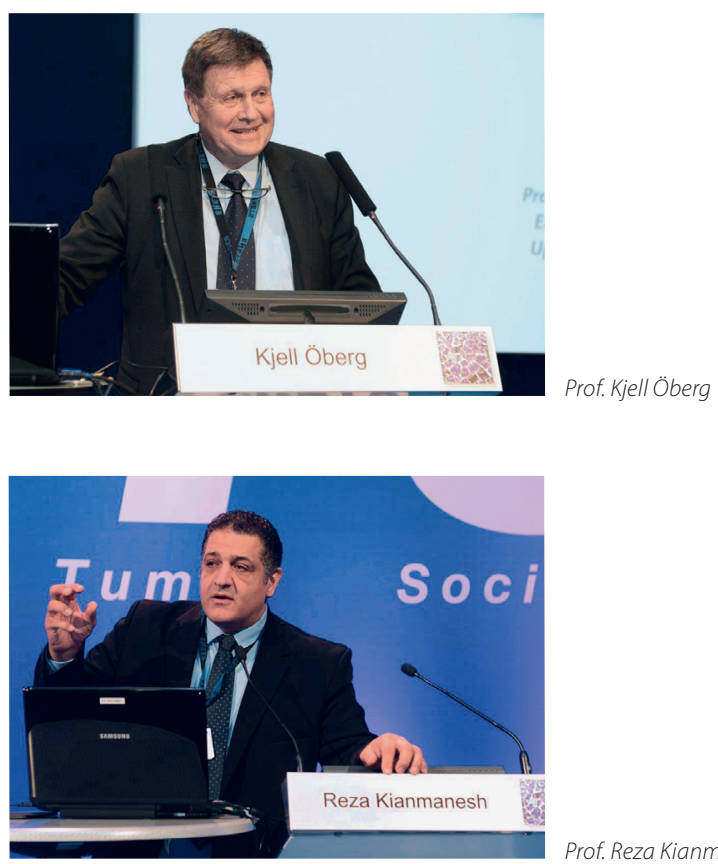

Prof. Reza Kianmanesh

use of GIP-R for diagnostics. However his work was not restricted to NET alone. ENETS congratulates Prof. Reubi and is proud to include him as an Honorary Member.

Other highlights were Session 4 ENETS/EANM (European Association of Nuclear Medicine) Joint Symposium: PRRT - Peptide Receptor Radionuclide Therapy, where a very intriguing debate was set off between the pros and cons from Prof. Bartsch, Germany, and Prof. Kjell Öberg (see photo above), Sweden, concerning 'PRRT Versus Medical Therapy for Intestinal NET'.

Session 5 on Friday, 11 March covered very exciting surgical debates. 'Transplant Versus Liver Resection' between Prof. Andreas Pascher (Charité - Universitätsmedizin Berlin, Germany) and Prof. Vincenzo Mazzaferro (National Cancer Institute, Milan, Italy) sparked a needed discussion. Prof. Mazzaferro covered the PRO aspects titled 'Liver Transplantation in NET'. In his talk he explained how 'the complexity of metastatic NET impairs surgical treatment comparison through RCTs'. Prof. Andreas Pascher in turn countered in opposition. One of the many views he stated was: (1) 'to date, there is no single patient population for which a clinical benefit in terms of survival, DFS, QOL, and cost effectivity can be proven', and (2) 'those patients who do best after LT may be those who do not need it'.

During the second part of this Session, 'Intestinal Surgery in Patients with Unresectable Liver Metastases', Dr. Graeme Poston (University Hospital Aintree UHA, Liverpool, UK) gave his PRO views on 'Resection of Primary Tumor', while Prof. Reza Kianmanesh (see photo above) (R. Debré University Hospital, Reims, France, and currently ENETS Executive Committee Member) covered the CON view.

During the discussion, an interesting question resulted out of the debate raised by Prof. Thomas J. Musholt (Germany) from the audience. He asked: 'You emphasized in your talks that patients should be asymptomatic and that their liver metastases should be irresectable. Could you comment on the percentage of patients who have no symptoms and have ir-

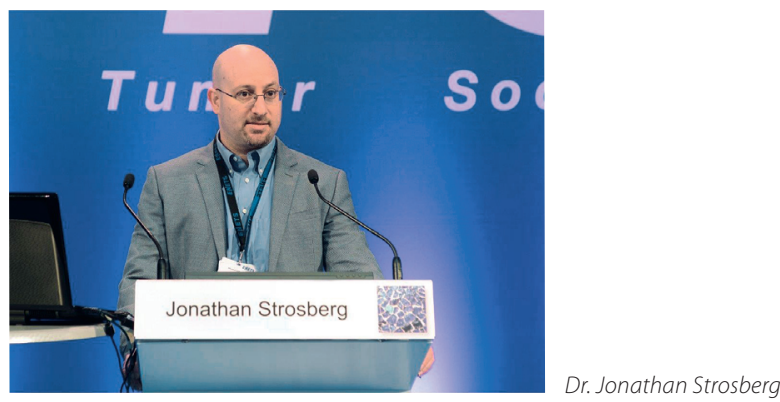

resectable liver metastases? How do you discriminate, for example, that the symptoms are related to the bowel rather than to the liver metastases, in patients with carcinoid syndrome?'

Reza Kianmanesh remarked that this is a good question and ENETS quotes him as saying: 'First of all, carcinoid symptoms are not related to the primary, so carcinoid crisis is out of this. 30\% of patients or more will have carcinoid syndrome and they will include it. It's not related to the primary, even if you resect primary. It does not affect the carcinoid syndrome unless there is a huge bulky lymph node. So the point is, to see and check the patients with systematic CT scans or entero scans etc. If there are no signs, then CT scans or opacification directly, we would say that there might be a little bit of pain, but it's not the all-inclusive syndrome...' Thomas J. Musholt commented and clarified his view that CT scans often do not correlate with the actual in-situ findings and ENETS quotes him: '... we operate on a lot of patients with neuroendocrine small bowel tumors and noted that often the tumor extent is not seen in the CT scan, but intraoperatively one can appreciate the impending complications such as vascular occlusion and venous congestions by lymph node metastases. A lot of these patients have diffuse abdominal pain, and in fact, more than $70 \%$ of my patients in my clinic complain of pain or diarrhea'. Kianmanesh asked Musholt whether he operates on them? Musholt replies 'yes'. Kianmanesh finalized: 'So if you include patients with no pain you will operate on them, because it became symptomatic....

Session 8, 'What's New in the Field?' on Friday was accompanied this year by four brief presentations covering the trials 'NETTER -1 Phase III' by Prof. Jonathan Strosberg (see photo above) (USA), a TELESTAR trial by Prof. Dieter Hörsch (Germa-ny), and a study titled 'Sunitinib in Patients with Advanced, Progressive Pancreatic Neuroendocrine Tumors: Final Overall Survival Results, from a Phase III Randomized Study', by Prof. Eric Raymond (France) and 'Efficacy and Safety from a RADIANT-4 Subgroup Analysis' by Prof. Simron Singh (Canada). To highlight at least one of the aforementioned trials, Jonathan Strosberg's delivered a lecture where he described 'NETTER -1 Phase III' as the first randomized prospective trial analysis of radiolabeled somatostatin analogues, specifically ${ }^{177}$ Lu-DOTATATE, which showed a very striking improvement of progression-free survival, striking improvement on overall response rate and a strong suggestion of overall survival improvement that needs to be confirmed on final analysis. He concluded that for pa-tients progressing on first line somatostatin analogues, "177Lu-DOTATATE represents a very promising form of therapy bothin terms of efficacy and safety'.

To follow the above mentioned talks and all other talks, please visit the MY ENETS member's area to view the webcasts:www.enets.org/my_enets.html. 


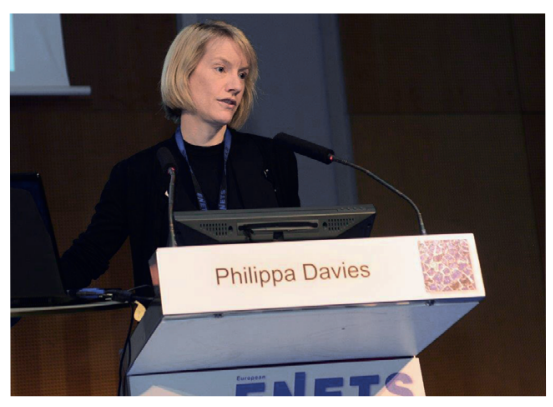

Philippa Davies, UK (ENETS NET Nurse, Chair)

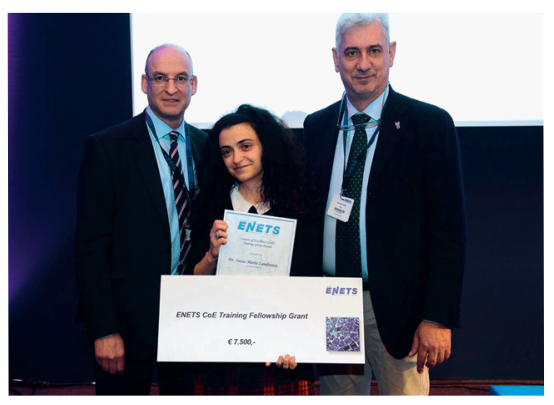

oana Lambrescu with Caplin (left) and Falconi (right)

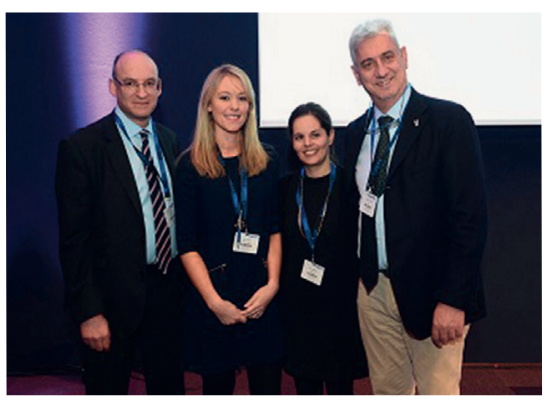

Abstract winners Childs (middle left) and Marinoni (third right) with Caplin (far left) and Falconi (far right)

\section{ENETS NET Nurse Symposium} written by Philippa Davies

The ENETS NET Nurse Program has developed over the last few years, with one of the main aims for the program to encourage nurse led research in NETs. The meeting is an ideal opportunity for nurses and other healthcare professions from throughout Europe to meet and share ideas related to best practice and potential research plans. This year's program was varied and speakers were from throughout Europe including Finland, the Netherlands, Sweden and the UK.

Wide-ranging topics were presented highlighting the complex nature of NETs. This included presentations identifying the use of blood measurements for 5 HIAA instead of the use of 24-hour urine tests, and a summary of the exciting future developments related to genetics and liquid biopsies. The UK National Cancer Patient Experience Survey results were discussed, the first of its kind for NETs. Nurse led research was presented related to the patients experience of the impact of chemotherapy and the delay of diagnosis for patients with NETs.

The discussion following the presentations highlighted many interesting areas for future collaborative research and development.

The Nurse Program at ENETS continues to grow and will include 'ENETS Nurse Workshop' next year to continue to promote research, education and standardization of nursing care and allow more opportunities for nurses to meet and discuss new ideas. For more information about ENETS NET Nurse, please visit http://www.enets.org/net_nurse_ group.html.

\section{ENETS Grant Awards}

The Grants and Awards Ceremony was carried out on Friday, March 11th 2016 where Henning Jann (Berlin, Germany), recipient of the first ENETS Centers of Excellence (CoE) Excellence Academy Fellowship, received his award amounting to $100,000 €$ for his project titled 'Molecular Patterns of Lymphogenic versus Hematogenic Metastasis in Neuroendocrine

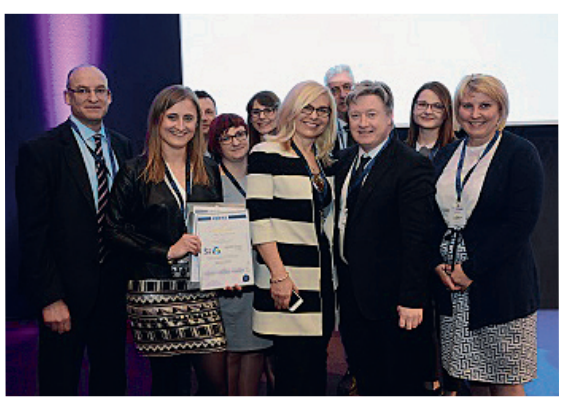

Katowice - New ENETS Center of Excellence
Neoplasias'. Joakim Crona (Uppsala, Sweden) received his award for the Young Investigator Grant amounting to $50,000 €$. His project is titled 'Molecular Mechanisms in the Malignant Progression of Neuroendocrine Tumors - Correlation with Mutagenic Therapy?'. ENETS looks forward to hearing more from both recipients in the future. Please refer to the ENETS website for more information on grant and fellowship programs: http://www.enets.org/grants_and_awards.

\section{Congratulations also went to Dr. loana Lambrescu (see photo above)} (Romania), who was awarded the CoE Training Grant Fellowship.

Additionally, the recipients for best Oral Abstracts in the category for Basic Science were Dr. Alexa Childs (see photo above) (1st place) and Dr. Ilaria Marinoni (see photo above) (2nd place). For Clinical, it was Guillaume Nicolas (1st place) and Jan Maarten Van Der Zwan (2nd place).

Best Poster prizes were awarded to Dr. Jerome Cros (1st place, Basic Science), Dr. Joakim Crona (2nd place, Basic Science), Maike Nieser (3rd place, Basic Science), while for the clinical posters it was René Pschowski (1st place), Ingrid Marie Holst Olsen (2nd place) and Christos Toumpanakis (3rd place).

Congratulations also go to the newly audited ENETS Centers of Excellence (CoE) from Katowice, Poland, headed by Prof. Beata Kos Kudla, to Southampton, UK, headed by Prof. Thomas Armstrong, and to Sheffield, UK, headed by Prof. J. Newell-Price.

Last but not least, congratulations go to the Travel Grant winners: Mauro Cives (Italy), Simona Falletta (Italy), Arooj Fatima (Pakistan), Elisabetta Grego (Italy), Thibault Kervarrec (France), Adrian Lock (Germany), Ariana Madani (The Netherlands), Francesca Muffatti (Italy), Roberta-Elisei Rossi (Italy), Yuhong Wang (China), Yu-Qing Zhang (China), Alessandra Zilli (Italy). 


\author{
Thank you to the 13th Annual ENETS Conference Scientific \\ Organizing Committee 2016 \\ - Martyn Caplin, GBR \\ - Rocio Garcia-Carbonero, ESP \\ - Kjell Öberg, SWE \\ - Wouter de Herder, NET \\ - Massimo Falconi, ITA \\ - Reza Kianmanesh, FRA \\ - Dermot ÓToole, IRL \\ - Marianne Pavel, GER \\ - Aurel Perren, SUI \\ - Bertram Wiedenmann, GER
}

Thank you to the Annual Conference Barcelona 2016 ENETS Team

- Matgorzata Szott-Emus

(Project Manager and Accountant for

ENETS Annual Conferences)

- Simon Hirschmann

(Technical Manager)

Vanessa Tatum (Program Development

and Communication, ENETS Office)

The conference once again brought together experts from all over the world and the fields of oncology, pathology, radiology, nuclear medicine, endocrinology, surgery and gastroenterology were all represented. ENETS aim was to have offered participants a chance to gain needed knowledge in order to implement this in their daily work, and above all, to assure high quality and optimal treatment for NET patients. Next year's 14th Annual ENETS Conference will take place at the CCIB in Barcelona, Spain, 8-10 March 2017. For more information, please visit http://www.enets. org/annual_enets_conference.html.

\section{ENETS Guidelines 2016}

The ENETS Guidelines 2016 were published this April (Neuroendocrinology, Vol. 103, No. 2, 2016).. This is the outcome of the ENETS Advisory Board Conference, which took place in Vienna, Austria, on the 30th and 31st October 2014. Prof. Martyn Caplin (currently ENETS Vice-Chairman and former Chairman 2014-2016) initiated the 4th ENETS Consensus Guidelines Conference, and Prof. Dermot O'Toole (current ENETS Chairman Elect) has taken on great efforts in managing the ENETS Guidelines, seeing it through from the beginning all the way to its publishing. Through the Advisory Board members' contribu-

\begin{tabular}{l} 
ENETS GUIDELINES \\
Current ENETS Guidelines \\
Past Guidelines \\
ENETS Standards of Care \\
\hline Current ENETS publications
\end{tabular}
tions as authors and co-authors, the ENETS Guidelines in its 4th update can now be viewed via the Neuroendcrinology Journal (Karger AG). The areas include neuroendocrine neoplasm-related topics by sites of origin or stage: gastroduodenal, midgut (including appendix), hindgut, functional pancreatic, non-functional pancreatic, and two final sessions that covered liver and other distant metastases from neuroendocrine neoplasms of any origin. A separate session was devoted to neuroendocrine high-grade tumors and carcinomas.

'These ENETS Guidelines provide important updates from world leaders in the field of NETs to compliment former consensus conferences in providing practical clinical evidence for NET patient management. The provision of useful diagnostic and therapy algorithms will also help to simplify everyday clinical practice. All participants equally contributed a great effort, and the delegates generously devoted their time, experience and enthusiasm to building the following Consensus Guidelines.' (Source: Neuroendocrinology 2016;103:117-118)

As an ENETS member you can view the ENETS Guidelines via MY ENETS via http://www.enets.org/my_enets.html. Should you wish to become a member, please either send an email to info@enets.org or visit http:// www.enets.org/register.html.

\section{ENETS Involvement in European Reference Network (ERN)}

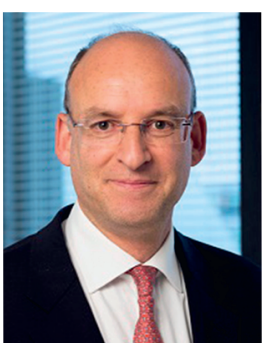

Prof. Martyn Caplin, ENETS Vice-Chariman
ENETS is currently in the midst of applying for the European Reference Network (ERN). Prof. Martyn Caplin, who is heading this, points out that this application process is a very important step for ENETS. As many of you may know, in the last year, the Neuroendocrine Tumors community has been working at a political level to build support for the community and also specifically to support this application. Prof. Martyn Caplin has been active in pushing this forward for ENETS. He believes that an effective ERN for NETs could contribute tremendously to improving standards of care for patients with NETs in Europe by increasing the likelihood of access to specific NETs medical expertise in order to lead their treatment.

This is especially important in countries where little NETs expertise exists, as the network should facilitate cross border care. This will not detract from the ENETS Center of Excellence (CoE) program. Anticipated, is that the CoE will be a paradigm for the ERN and that the importance of the Centers of Excellence will be highlighted.

Currently, there are three objectives that the EU institutions have for ERNs:

- apply EU criteria to tackle rare diseases requiring specialized care

- serve as research and knowledge centers treating patients from other EU countries

- ensure the availability of treatment facilities where necessary

'The European Reference Networks (ERNs) for rare diseases should serve as research and knowledge centers, updating and contributing to the latest scientific findings, treating patients from other Member States and ensuring the availability of subsequent treatment facilities where necessary. The definition of ERN should also reflect the need for services and expertise to be distributed across the EU' (source: http://ec.europa.eu/health/rare_ diseases/european_reference_networks/erf/index_en.htm\#fragment0). 


\section{Centers of Excellence (CoE)}

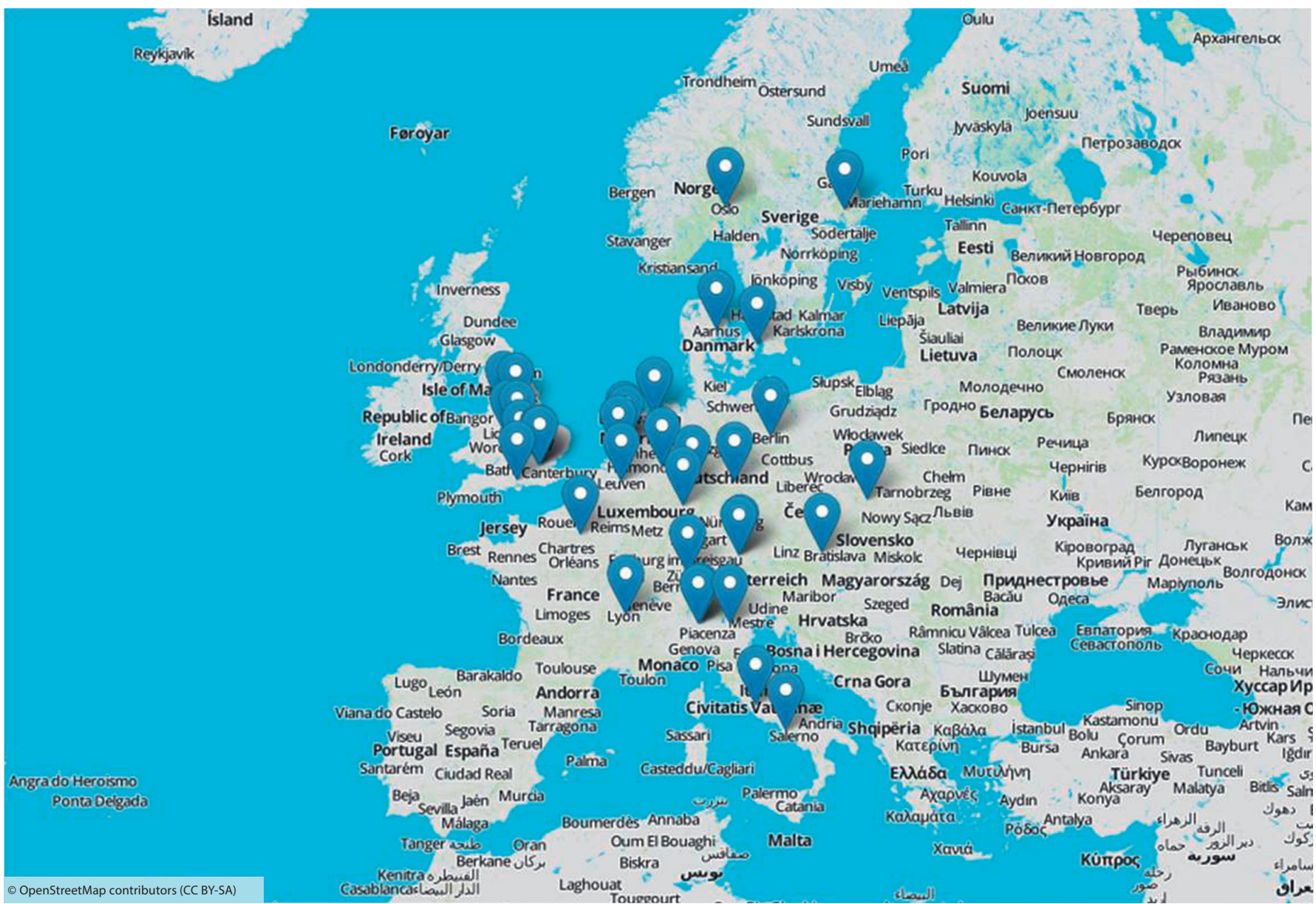

Map of the ENETS COES, May 2016

The Centers of Excellence (COE) have continued to grow and succeed in contributing to improve care and survival for NET patients. As of 2016, there are $37 \mathrm{CoEs}$. The last three new centers were awarded their certificates on March 11th 2016 (please read above 'Grant Awards'). To understand why ENETS is proud of this endeavor is to know that the centers who received a certification called ENETS-CERT, have to undergo strict auditing processes to receive the certification for high quality standards.

The re-audits are implemented every two years to ensure that a center offers excellent medical treatment.

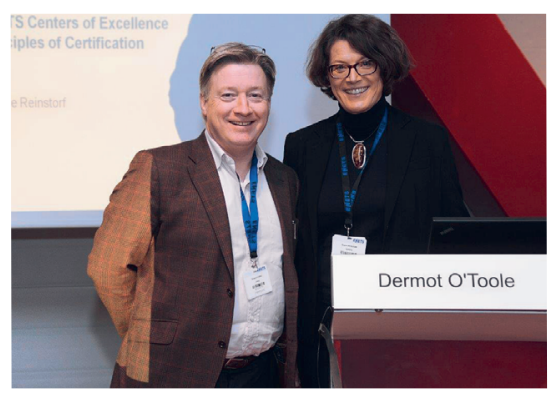

Dermot O'Toole and Regine Reinstorf
The auditing procedures have been developed with the support from the GSG company. Patients with neuroendocrine tumors seek these certified centers in order to receive the best medical consultation and treatment.

The importance, however, does not only lie on the ENETS-CERT itself, but also because of the fact that CoEs collaborate with one another and engage medical professionals from different medical disciplines to participate in making ENETS a truly multi-disciplinary society.

ENETS is increasingly attracting worldwide participation and it is a pleasure to see that colleagues not only from the USA and Americas, but also from Australasia and Far East are engaged, as well as the strong association which ENETS is developing with China. Prof. Dermot O'Toole, who leads this task force and Dr. Regine Reinstorf (GSG), who manages the audit processes (see photo left) are continuously striving to ensure that the CoE's safeguard the practicing of the ENETS-CERT audit guidelines.

\section{History}

The CoE was originally initiated by Prof. Bertram Wiedenmann (current ENETS Treasurer) in 2007. In this respect, the first ENETS CoE was accredited in 2009 at the Department of Hepatology and Gastroenterology at the Charité - Universitätsmedizin Berlin in Germany. 


\section{MY ENETS}

The member's area 'MY ENETS' has been recently updated and ENETS is looking forward to hearing from its members on how it has helped them find the information they need to learn more about ENETS projects, e.g. ENETS Registry, Centers of Excellence (CoE) processes and application guidelines, as well as view the ENETS Guidelines in the Neuroendorcinology Journal. Please stay tuned for more updates in 'MY ENETS', which will soon aim to offer E-learning directly within two clicks, allowing one to receive CME credits, managing your profile member account and accessing the 13th Annual ENETS Conference 2016 webcasts. Please send any suggestions for the 'MY ENETS' area to info@enets.org.

\section{ENETS NET Summer School}

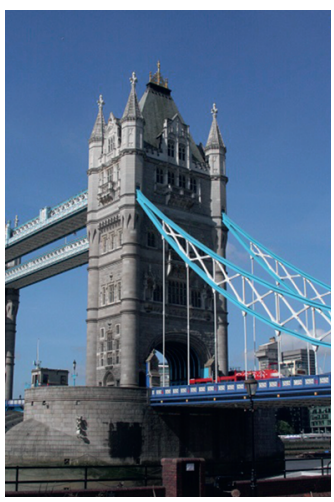

ENETS encourages its young researchers to register for the 3rd ENETS NET Summer School, which will take place at the Royal Free Hospital in London, United Kingdom, from 11-14 September 2016. The program in London will include: clinic experience, MDT, update on NET advances and ward PRRT, research overview. The application deadline is 17th of June 2016 at 23:59 CET.

Last year's ENETS Summer School took place in Paris (Clichy), France and was headed by Prof. Philippe Ruszniewski. The 2-day event was considered a success and was positively reviewed by the recipients.

For more information on ENETS Summer School please visit http://www.enets.org/enets_net_summer_school_uk.html.

\section{Save the Dates!}

The next call for ENETS abstracts, grants and awards within the framework of the 14th Annual ENETS Conference, which is taking place 8-10 March 2017, will begin soon.

\section{ENETS}

\section{SAVE THE DATE}

ENETS Centers of Excellence Academy Fellowship Grant Application - Submission begins 1 May 2016 ends 30 June 2016

$3^{\text {rd }}$ ENETS Summer School 2016

Royal Free Hospital, London, September 2016*

- Submission begins 1 June 2016 ends 1 August 2016

\section{$14^{\text {th }}$ Annual ENETS Conference for the Diagnosis and Treatment of Neuroendocrine Tumor Disease}

\section{8 - 10 March 2017 | Barcelona | Spain}

\author{
- ENETS Annual Conference Early Bird Registration \\ begins 1 September 2016 \\ ends $\quad 30$ November 2016 \\ - ENETS Annual Conference Regular Registration \\ begins 1 December 2016 \\ ends 10 February 2017 \\ - ENETS Annual Conference Abstract Submission \\ begins 1 September 2016 \\ ends 1 December 2016 \\ - ENETS Annual Conference Travel Grant Submission \\ begins 1 September 2016 \\ ends 1 December 2016 \\ - ENETS Annual Conference Grants and Awards Submission \\ begins 1 November 2016 \\ ends 8 January 2017 \\ for - ENETS CoE Training Fellowship Gran \\ ENETS CoE Young Investigator Grant \\ - ENETS Translational Grant - partially industry - sponsored \\ - ENETS Håkan Ahlman Award
}




\section{Conference Photos at a Glance!}

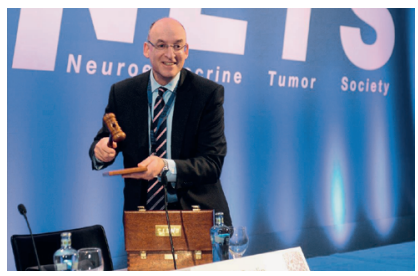

Former ENETS Chairman M. Caplin officially announces the handover of ENETS chairmanship to M. Falconi

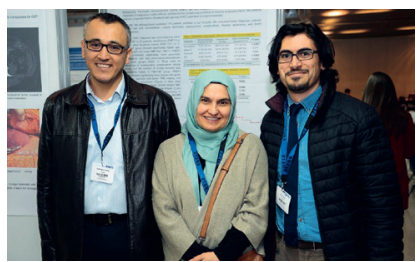

Participants during poster reviewing

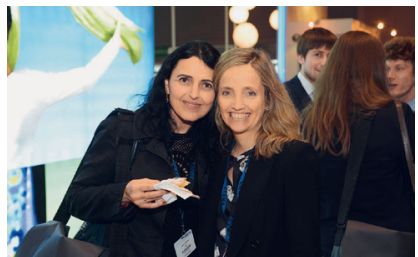

R. Garcia-Carbonero, right, and S. Glasberg, left, enjoy a moment for talks amongst colleagues

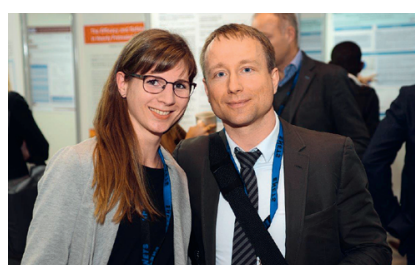

D. Kaemmerer, right, touring the poster session and enjoying a break

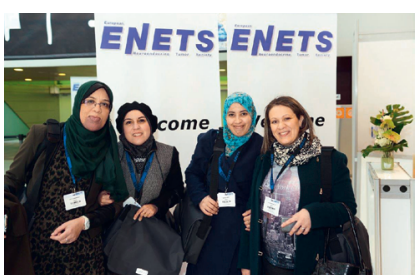

ENETS welcomes participants from all of the world to network

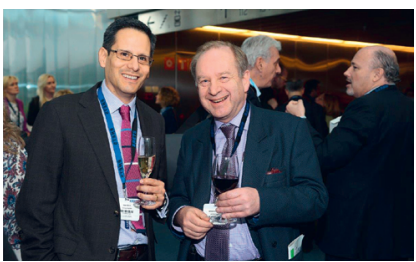

N. Reed, right, ENETS abstract committee lead, enjoys a break during reviewing

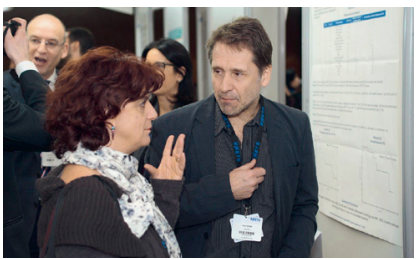

Abstract and poster author in action during Q\&A

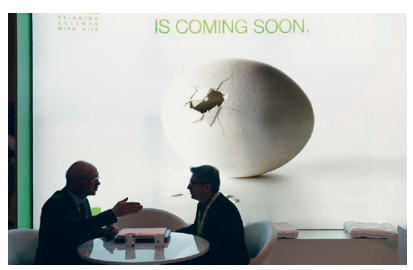

Booth from AAA

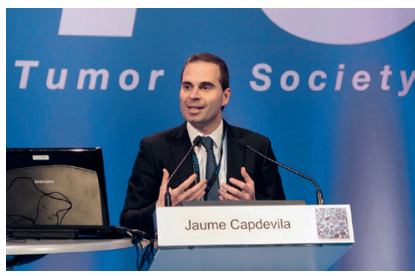

Lecturer J. Capdevila

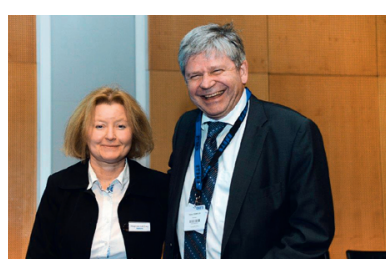

M. Szott-Emus, ENETS conference project manager and accountant, left, receives a special thanks for her many years work announced by T. Steinmüller, ENETS auditor, right, during the General Assembly

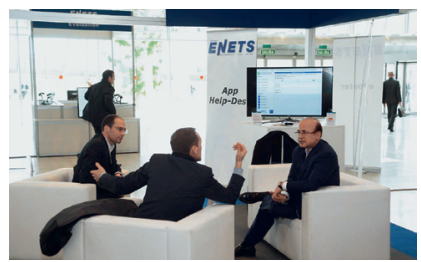

ENETS booth and lounge which is also used for networking in the main hall

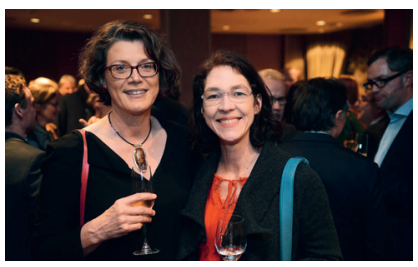

R. Reinstorf, left, CoE coordinator, and V. Tatum, right, conference program coordinator and ENETS administrator catch up for a brief chat

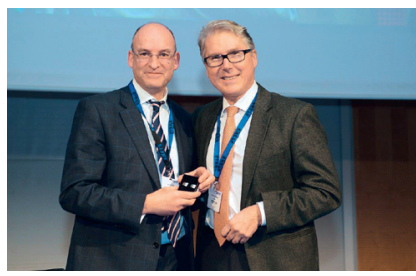

B. Wiedenmann, ENETS Treasurer, right, hands over 'ENETS' cufflinks to M. Caplin, left, for his term as Chairman

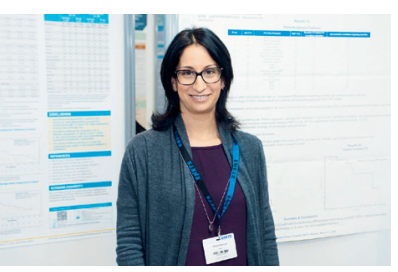

Abstract and poster author waiting for Q\&A

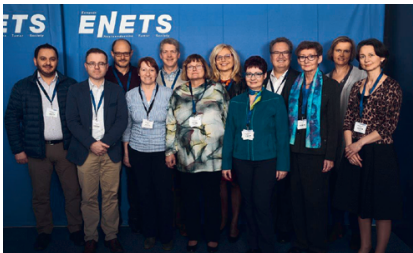

ENETS NET Registry Group

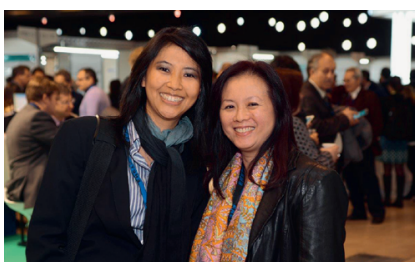

Participants enjoying time-out to talk during the conference in the poster area 


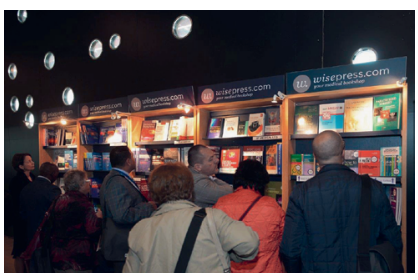

The Wisepress book shelf was a worthwhile visit for many participants in the exhibition

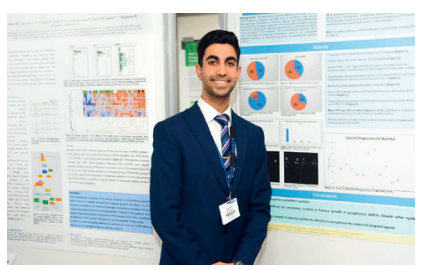

Abstract and poster author waiting for Q\&A

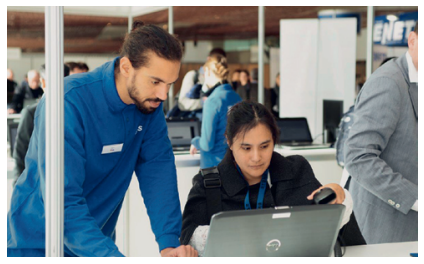

ENETS strives to improve its program every year and asks participants for feedback

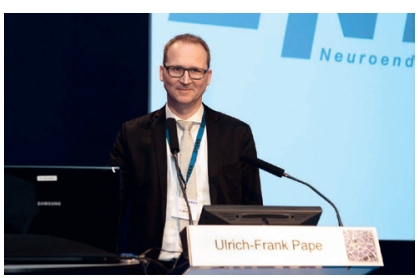

U. Pape lecturing during the PG course on 9 March 2016

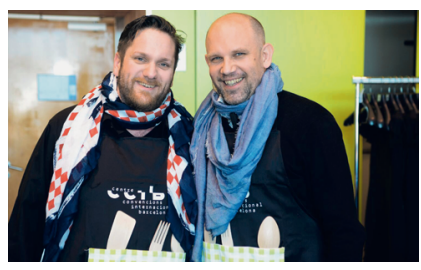

ENETS conference technical manager S. Hirschmann, left, and colleague C. Hübner, right

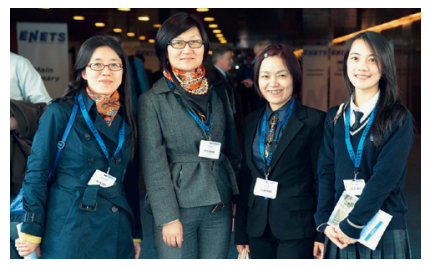

Participants meet and greet during the ENETS Welcome Ceremony

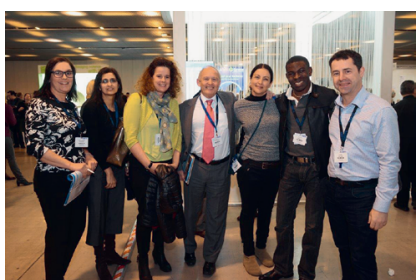

A. Grossman, center, surrounded by colleagues during tea break

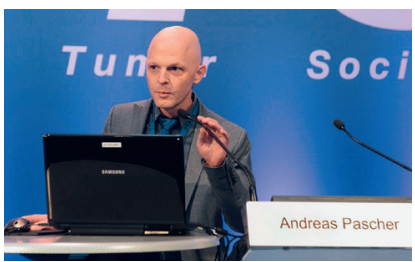

Lecturer A. Pascher

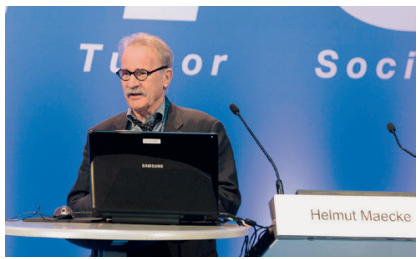

H. Maecke during his lecture

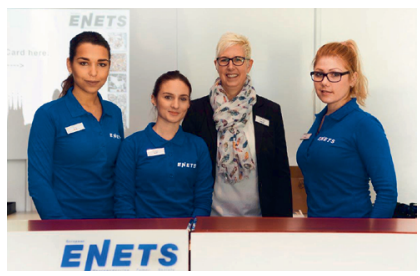

The ENETS registration team lead by U. Knell, center-right

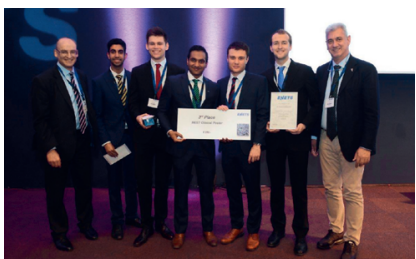

Poster winners for the group of C. Toumpanakis

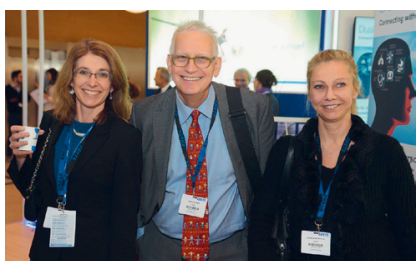

Participants enjoy a photo during Poster Sessions

Imprint

Executive Committee: Chairman: Prof. Massimo Falconi | Vice-Chairman: Prof. Martyn Caplin | Chairman-Elect: Prof. Dermot O’Toole | Treasurer: Prof. Bertram Wiedenmann | Scientific Secretary: Prof. Aurel Perren | Members: Prof. Rocio Garcia-Carbonero, Prof. Eva Tiensuu Janson, Prof. Reza Kianmanesh, Prof. Dr. Marianne Pavel

ENETS Newsletter Imprint: Editor: Vanessa Tatum | Proofread: Malgorzata Szott-Emus, Ulrike Knell | Layout and Publishing: Karger Publishing, Basel, Switzerland

ENETS Office: Charité - Universitätsmedizin Berlin | Campus Virchow-Klinikum | Department of Gastroenterology and Hepatology | Augustenburger Platz 1 | 13353 Berlin, Germany |

Tel. +4930450553096 | Fax +4930450553942 |E-Mail info@enets.org

Copyright: The ENETS Newsletter and all individual articles and illustrations in it are copyrighted. Each and every use outside the strict limitations of copyright law shall require the approval of the publisher and the copyright owner. This shall also apply to reproduction by copying, recording in electronic databases and distribution on CD ROM and on the Internet. 